\title{
Multiple Means of Expression Made Available by Digital Media
}

\author{
Karen Bosy \\ RCA, London \\ Garden House \\ Dorando Close \\ London W12 7TU, UK \\ karen.bosy@network.rca.ac.uk
}

\author{
Cristina Portugal \\ CNPq, National Council for \\ Scientific and Technological \\ Brasília/DF \\ Brazil \\ crisportugal@gmail.com
}

\begin{abstract}
This work considers visualization of diverse media by practitioners using a prescribed method of video-making to express their own practice. Practitioners invited to contribute represent diverse fields in art and design practice and may usually use other means of expression including text, mark making, object, film as well as video. The aim is to encourage reflection on the articulations between the multiple means of expression made available by digital media. A series of videos was produced exploring a subjective discourse where one can perceive this media as an extension of the physical, or an environment where a language can be shared. The prescribed method allows expression of curiosity, creativity, cooperation and experience of the ludic by enabling each individual to create their own discourse.
\end{abstract}

Art. Video. Media. Narrative. Visualisation.

\section{INTRODUCTION}

The possibility to develop this collaborative project arose through a fortuitous meeting and subsequent conversations between Karen Bosy, PhD student in the School of Communication at the Royal College of Art (RCA) in London and Cristina Portugal, holding a postdoctoral degree (2017-2018) at the same University.

During this year Bosy and Portugal engaged with postgraduate community at the College and participated in the weekly research seminars, Methods of Intent, to better understand the ways in which methods and methodologies function in the School of Communication's PhD group research. This led to the development of the method, which is applied to this project and informs the work.

The following quotation from Marshall McLuhan (1988) led to reflection on the multiple means of expression made available by digital media.

'Media as an extension of self, that is, as technology extends natural human abilities. Technologies are not simple additions of human existence. These technologies change how humans think, feel and act, even the individual's perception and information processing. New Technologies have had psychological, physical and social effects. We shape our tools and our tools shape us'.

This paper will be presented as a series of digital discourses in video format. The question that guided this work progressed from the reflection that our cognition is modified as we move away from physical material. The aim or purpose of this research is to encourage reflection on the articulations between the multiple means of expression made available by digital media and draw out underlying issues of the information gained and lost in changing modes.

This collaboration developed from a discussion initially centred around organising a series of interviews on the subject of media, and specifically choice of media employed within a practice, and the ways in which this may contribute to meaning, creating interpretations of a resultant work. Practitioners who were invited to contribute represent diverse fields in art and design practice, and may usually use other means of expression including text, mark making, object, and film, as well as video. In this work, these practitioners explore their individual use of media through a prescribed method of digital video to allow concepts to come into view, and aiming to draw out underlying issues and advantages of a shift in 
media. The decision to ask contributors to use video as a way to represent their own medium and way of working moved this project away from a primarily text-based format. Contributors are asked to consider the prompt of a glass of water for a video-based active reflection on their practice.

\section{METHOD}

Contributors use a glass of water, a prop often present during interviews, as a start point or prompt. How the resultant work is completed is left to the contributors. The videos can be layered, for example through montage editing or using green screening, or, for example, a single long clip may be used. Videos may be silent or have sound, and all alternative ways that may be found were welcome. The resultant moving image works are of maximum 3-minute duration.

Videos are contributed as links to the online video platform Vimeo, and gathered together on a blog page. Videos remain in the practitioners' Vimeo accounts and can be withdrawn at any time by the contributors by changing the link to their video or changing the privacy settings within their individual Vimeo accounts.

\section{FINDINGS/RESULTS}

A series of videos was produced exploring a subjective discourse where one can perceive this media as an extension of the physical, or an environment where a language can be shared. Assuming that each medium requires the use of different senses and also different levels of engagement, McLuhan explains 'the Medium is the Message' encompasses the idea that media and not their content should be the focus of media studies, since media format changes responses and the information it conveys.

As a collective, and in other ways dispersed, presentation of Vimeo links within a blog format, these videos form a subjective discourse and an experiential space within the digital site. As James Lingwood (1995) explains, '...we learn to interpret the conversations associated with photography, cinema, painting, street signs and so on. These systems...lead us to believe that the world is a fixed and orderly place...' (as quoted by Grant Kester, Rachel Whiteread's House, 1995, p.20). Although some practitioners included in this project use video in their practice, for most it is not a central medium. Similarly, although some practitioners included in this project use water as a device within their practice, these videos represent a shift away from practitioners' more familiar explorations. Defamiliarising practice through using the prescribed media (video) and the prompt (the glass of water) this project allows space for seeing 'anew' (Boym 2010).

In order to progress this project, some experiments using video and a particular method of videoing were undertaken using a submerged camera, a method of videoing from within my documentarist art practice. These experiments led to the development of the video Ephemeral and then Nature. Filming in this way, the surface of the water as it moves against the camera lens indicates another surface: the surface plane of the image. The containing vessel, in this case a glass, can be used to create a frame. These techniques of indicating the surface plane of the image and framing, distance the video image by 'imposing a form on reality', as Catherine Russell (1999, p.168) explains in her book Experimental Ethnography. This can allow an in-between space to be presented and a recording of a proposal rather than recording reality.

The initial Seminar videos, Ephemeral and Nature, were followed by invited practitioners contributing to this project using the glass of water as a prompt and video as a prescribed method. In the videos, the connection to the prompt is at times obvious and at times more enigmatic. Some practitioners contributed a brief text (which was welcomed though not prescribed), and these share a reflection on reality and process as well as considerations of ephemerality and materiality and other ideas particular to their practices. Practitioners were invited to contribute videos in the form of a Vimeo link and these are collected on a blog page. Documentarist presentation on a website can be exemplified by artist and filmmaker Miranda July's (2010) Learning to Love You More, a collection of contributed recordings of prescribed actions and places. These, framed by the website, construct an in-between site in the digital space.

Although collected, Seminar's videos are also dispersed; when clicking each link a different Vimeo account is accessed. The spectrum of collection and dispersal is explored further in Collective|dispersed, another artwork by KM Bosy, found elsewhere on the same blog. Contributors to Collective|dispersed similarly use a glass of water as a start point but without the caveat that this be in some way relevant to their practice. Some practitioners, for example Joanna Roykovska and Kelly Spanou, have contributed separate Vimeo links to both Seminar and Collective|dispersed, as listed below. Debbie Poon's exploration of the vessel was contributed initially to Collective|dispersed, although as this video reflects on the practitioner's practice, it is also included within Seminar. 
The prompt (the glass of water) in relation to their practice and a prescribed media (video) creates a space for practitioners to see 'anew' (Boym 2010). Parallels may be drawn between this project's strategy to that employed by Strangely Familiar: Narratives of Architecture in the City, a symposium and exhibition (1995-1997) where invited contributors from diverse practices shared a 'narrative about a specific place in a city and an object related to that place'. As architect and theorist Jane Rendell explains, 'Each interpretative stance revealed a place that was 'strangely familiar', familiar because certain aspects were already known, strange because they were being revealed in new ways.' Rendell, discussing the strategies employed during the Strangely Familiar exhibition, explains that Doreen Massey argued for an understanding of place as 'unfixed, contested and multiple'. Searching for a way to avoid 'essentialising tendencies', Rendell draws on Massey and other theorists, who 'stress the importance of understanding the specifics of particular sites and places but only in relational terms...' In Seminar, the videos fulfil a similar function to that fulfilled by the narratives and objects in Strangely Familiar within the exhibition space. Each video reveals a defamiliarised aspect of the prompt that forms a relational context within the relational space of the blog site, when framed by the blog site and placed in a relationship, as a form of subjective understandings in a discourse that is significant as the time of completion becomes indeterminate (Castro 2012).

The prompt (the glass of water) in relation to practice and a prescribed media (video) defamiliarises in order to see 'anew' (Boym 2010). Seminar's practitioners (contributors) and viewers share this experience, as we all look, think, judge and imagine connections to the prompt. In a collection of her papers, Space, Place and Gender, Doreen Massey (2007, p.265) explains that, 'the spatial is socially constituted' and created out of 'networks of relations at every scale...' In relation to Massey's concerns about the importance of theorising space as relational, parallels can be drawn between strategies employed by Strangely Familiar: Narratives of Architecture in the City and this project's strategies. In Seminar, videos rather than objects and texts document the tension between place and relational space. These videos contributed via dispersed Vimeo links, are gathered together and framed by the blog format, as subjective understandings in a discursive space.

\section{CONCLUSION}

Finally, this project encourages reflection on the articulations between the multiple means of expression made available by digital media, and draws out underlying issues of the information gained and lost in changing modes.

The prescribed method allows expression of curiosity, creativity, cooperation and experience of the ludic by enabling each individual to create their own discourse. Although there is no 'natural' way of interweaving texts, images, sounds and images, the video series presents a variety of media, from born-digital events to documentation of physical interventions.

As a result of the project a series of videos (see below) was produced that bring a subjective discourse where one can perceive the media as an extension of the self, an environment where language can be shared, as technology broadens the natural human skills and turns the natural environment into a fictional world. Technology is not a simple addition to human existence, but through technologies we can change the way we feel and act, can transform even the perception and processing of information, and this consequently modifies our cognition.

\section{SEMINAR AND COLLECTIVE | DISPERSED / VIMEO LINKS}

\section{Seminar}

Duchesne, C. "WATER." Vimeo. https://vimeo.com/309027627 (retrieved 3 March 2019).

Martin Ganzinotti, M. "Traces." Vimeo. https://vimeo.com/321858649 (retrieved 3 March 2019).

Loughlin, I. "Performance with a Mirror for Trees_Irene Loughlin." Vimeo. https://vimeo.com/320085568 (retrieved 3 March 2019).

Moody, Paul David John. Paul Moody A Glass of Frozen Water Begins to Thaw, 2019. https://vimeo.com/325215353 (retrieved 3 March 2019).

Poon, D. "Waiting By Water." Vimeo. https://vimeo.com/304246586 (retrieved 3 March 2019).

Roykovska, J. "Nude with Water." Vimeo. https://vimeo.com/106498159 (retrieved 3 March 2019).

Spanou K. kellyspanou. Possible Landscapes, 2016. https://vimeo.com/168541728 (retrieved 3 March 2019).

Van Bork, F., "CG movie 3 Min." Vimeo. https://vimeo.com/310846838 (retrieved 3 March 2019). 
Alram F., Portugal C., Bosy K., "Ephemeral." Vimeo. https://vimeo.com/288579211 (retrieved 3 March 2019).

Portugal C., Bosy K., Bosy T., Alram F., "Nature." Vimeo. https://vimeo.com/325255933 (retrieved 3 March 2019).

Bosy K. "Private." Vimeo. https://vimeo.com/295435678 (retrieved 3 March 2019).

\section{Collective|dispersed}

Bosy K. "Water Glass." Vimeo. https://vimeo.com/313882900 (retrieved 3 March 2019).

Poon, D. "Waiting By Water." Vimeo. https://vimeo.com/304246586 (retrieved 3 March 2019).

Roykovska J. "Water2 S." Vimeo. https://vimeo.com/186015357 (retrieved 3 March 2019).

Roykovska J. "Spiral." Vimeo. https://vimeo.com/112388382 (retrieved 3 March 2019).

Vukovic Smart M. "Fire Walk With Me." Vimeo. https://vimeo.com/316432814 (retrieved 3 March 2019).

Spanou K. kellyspanou. Sonar, 2016. https://vimeo.com/167542270 (retrieved 3 March 2019).

Vorá D. "Black River/Leveller." Vimeo. https://vimeo.com/317434079 (retrieved 3 March 2019).

\section{ACKNOWLEDGMENT}

CNPq - National Council for Scientific and Technological Development from Brazil, Bolsista de Produtividade de Pesquisa $(\mathrm{PQ})$ - Proc. $\mathrm{N}^{\circ}$. 7547547039015568To and School of Communication, RCA.

\section{REFERENCES}

Arendt, H. (1958) The Human Condition, 2nd edn. University of Chicago Press, Chicago, 1998.

Borden, I., Kerr, J., Pivaro, A. and Rendell, J. (eds) (1995) Strangely Familiar: Narratives of Architecture in the City. Routledge, London. See also: Jane Rendell [website].

http://www.janerendell.co.uk/books/strangely-

familiar (retrieved 25 January 2019).

Bosy, K. (2017) Intentions: Conversations, Experiences and Knowledge. Royal College of Art. https://www.rca.ac.uk/news-andevents/events/intentions-conversationsexperiences-and-knowledge/ (retrieved 11 March 2019).

Bosy, K. (2018) Seminar Collection / Means of Expression. Kmbosy.Com/Blog (blog), n.d. http://www.kmbosy.com/blog/seminar-collectionmeans-of-expression/ (retrieved 3 March 2019).

Boym, S. (2010) The Off-Modern Mirror, e-Flux, 19, October 2010.2 https://www.eflux.com/journal/19/67475/the-off-modern-mirror/ (retrieved 16 January 2019).

Burdick, A. et al. (2012) Digital Humanities. MIT Press, Cambridge, MA.

Castro, J. C. (2012) Playing the Spiral Jetty. Journal for Artistic Research, 2 (May 11, 2012). https://www.researchcatalogue.net/view/2387/238 (retrieved 16 January 2019).

Drucker, J. (2014) Graphesis: Visual Forms of Knowledge Production. Harvard University Press, Cambridge, MA.

Jenkins, H. (2006) Convergence Culture: Where Old and New Media Collide. New York University Press, New York.

July, M. (2010) Learning to Love You More. http://learningtoloveyoumore.com (retrieved 3 March 2019).

Kester, G. H. (2013) Conversation Pieces: Community and Communication in Modern Art (with a new preface). University of California Press, Los Angeles.

Lingwood, J. (ed.) (1995) Rachel Whiteread's House. Phaidon Press, London.

Massey, D. Space, Place and Gender. Repr. Cambridge: Polity Press, 2007.

McLuhan, M. and McLuhan, E. (1988). Laws of Media: the New Science. University of Toronto Press, Toronto.

Portugal, C. (2019) DXTDIGITAL

http://dxtdigital.com.br/dxt/index.html (retrieved 12 March 2019).

Portugal, C. (2013) Design, Educação e Tecnologia. Rio Books, Rio de Janeiro.

Portugal, C., Brunnet, N. (2016) Design and the creation of an Interactive Academic Space. In: Proceedings of the Electronic Visualisation and the Arts (EVA London) 2019.

https://ewic.bcs.org/content/ConWebDoc/56276 (retrieved 12 March 2019).

Russell, C. (1999). Experimental Ethnography. Duke University Press, Durham, NC. 